\title{
Н.к. Чернышова
}

\section{ПРОБЛЕМЫ АГИОГРАФИИ НА СТРАНИЦАХ ДУХОВНОЙ ПЕРИОДИКИ СИБИРИ НАЧАЛА ХХ в.}

\begin{abstract}
Рассматривается история возникновения на территории Сибири проектов двух агиографических сборников - «Нового Свято-русского Патерика» в Тобольске (1912) и «Сибирского» в Омске (1916); выделены факторы церковнообщественной и культурной жизни России начала XX в., определившие появление проектов: издание Московской Синодальной типографией «Житий святыху на русском языке, изложенных по руководству Четьих Миней Св. Димитрия Ростовского с дополнением из Пролога (Кн. 1-12. М., 1902-1911) и канонизачия святителей Сибирских Иоанна Максимовича, митрополита Тобольского, и Софрония Кристалевского, епископа Иркутского. Выявлены и проанализированы публикачии Тобольских, Томских, Иркутских и Омских епархиальных ведомостей, отразившие процесс развития возникиих идей.

Ключевые слова:_агиография, житийный сборник, Патерик, святые, святители, проект, А.И. Юрьевский (архиепископ Лоллий), архиепископ Сильвестр (Ольшевский), митрополит Мануил (Лемешевский), Н.Н. Кузнецов (архиепископ Алексий), Тобольские, Томские, Омские, Иркутские епархиальные ведомости.
\end{abstract}

Исследования последних лет позволяют говорить о «взрывном» характере развития агиографии в России на протяжении второй половины XIX начала XX в. ([1-3] и др.). Разыскание, а также создание и подготовка житийных текстов к публикации сопровождались активным изучением различных вопросов истории Православия, текстологии, а также богословских и культурно-исторических аспектов функционирования памятников. Как отличительная черта данного этапа агиографии исследователями отмечено широкое распространение на территории страны русских Патериков, созданных в середине XIX - начале XX в., [1. С. 314-315; 4; 5]. Современный специалист под «русскими Патериками» имеет в виду «собрания житий святых, подвизавшихся в одном регионе или происходивших оттуда. Жития в рус[ских] Патериках часто давались в кратком изложении, но эти издания ценны тем, что в них были включены святые, не встречающиеся в общих сводах, а также использованы малоизвестные рукописи местных хранилищ, краеведческая лит[ерату]ра и местные предания» [1. С. 314]. Появление такого рода агиографических сборников (Патериков) отмечено и в Сибири $[2,6,7]$.

Духовные периодические издания региона начала XX в. зафиксировали возникновение замыслов, отразили процесс подготовки житийных сборников данного жанра. Кроме того, на страницах епархиальных ведомостей присутствует и контекст, в котором вызревали данные проекты: духовные 
авторы представляли новинки появлявшейся агиографической литературы и обсуждали состояние и задачи сибирской агиографии.

Упомянем некоторые факторы, определившие развитие этих процессов в нашем регионе. Одним из таких факторов, по нашему мнению, явились перевод, подготовка и издание в 1902-1911 гг. Московской Синодальной типографией многотомного агиографического сборника житий святых святителя Димитрия Ростовского, призванное «служить духовнонравственным чтением верующего православного народа» и одновременно подводившее итоги работы русских духовных писателей Нового времени в области агиографии. На страницах епархиальных периодических изданий Сибири прежде всего появились рекламные объявления о поступлении сборника в продажу ([8,9] и др.). Практически сразу стали публиковаться рецензии на издание. В Тобольских епархиальных ведомостях в 1904 г. была напечатана статья молодого священника А.И. Юрьевского. Рецензент прежде всего отмечал значение издания для православного читателя России, подчеркивал его воспитательную функцию, ставя научное значение сборника на второе место: «Четьи-Минеи, излюбленные русским народом, известны с именем Св. Димитрия Ростовского и, как составленные мужем высокой духовно-подвижнической жизни, оне носят характер не историкоагиологического исследования, а полного глубокой психологии, картинного воссоздания подвижнического образа православных святых, так что читатели могут ясно видеть своим мысленным взором весь постепенный рост духовной жизни того или другого праведника» [10. С. 442]. Тобольский автор высоко оценил качество русского перевода сочинения и отметил некоторые недостатки церковно-исторического комментария [Там же. C. 444]. Епископ Тобольский и Сибирский Антоний (Каржавин) там же, на страницах «Тобольских епархиальных ведомостей», высоко оценил значение житийных текстов, изданных отдельными брошюрами на основе Четьих-Миней [11].

Приведем краткие биографические сведения о тобольском духовном писателе - будущем авторе «Нового Свято-русского патерика». Александр Иванович Юрьевский (1875-1935), уроженец г. Тобольска (?), в 1901 г. закончил Казанскую духовную академию кандидатом богословия и вернулся в Тобольск, где в течение нескольких лет принимал активное участие в историко-краеведческой деятельности Братства Св. Димитрия Солунского, был хранителем Тобольского епархиального древлехранилища, в 1906-1907 гг. являлся председателем Совета Братства. Большое число публикаций А.И. Юрьевского появилось на страницах Тобольских епархиальных ведомостей. В 1914 г. А.И. Юрьевский был переведен в Кишиневскую епархию смотрителем единецкого духовного училища. В 1921 г. А.И. Юрьевский принял монашеский постриг с именем Лоллий, в течение нескольких лет был участником обновленческого движения, от которого отошел в 30-е гг., и, принеся покаяние, воссоединился с канонической Церковью. Автор статьи «Православной энциклопедии» называет А.И. Юрьевского знатоком истории Восточных церквей первых веков хри- 
стианства. Скончался епископ Лоллий в г. Ржеве в 1935 г. [6. С. 202-213; 12. С. 41].

Мы предполагаем, что именно издание сочинения Св. Димитрия Ростовского послужило непосредственным толчком для А.И. Юрьевского к созданию «Нового Свято-русского Патерика», который он, по-видимому, рассматривал как попытку продолжения труда знаменитого писателя ${ }^{1}$. А.И. Юрьевский в рамках деятельности Братства занимался изучением источников по агиографии Сибири и опубликовал ряд сочинений о сибирских святых и подвижниках благочестия на страницах епархиальных ведомостей и отдельными изданиями $[13,14]$.

В 1912 г. члены Совета Тобольского епархиального Братства протоиереи Д. Смирнов и К. Киановский, обсуждая замысел и значение созданного их земляком «Нового Свято-русского Патерика», писали: «Эту высокую задачу - ознакомить народ с жизнью и трудами новейших подвижников, нередко в тиши и неизвестности совершавших великое дело своего спасения и воспитания своих соотечественников в преданности Закону Божию и заветам святых отцов и берет на себя Тобольское епархиальное братство Св. Димитрия Солунского, приступая в настоящем (1912) году к изданию составленного священником Александром Юрьевским «Нового Свято-русского Патерика» [15]. Авторы статьи выражают надежду, что подготовленный житийный сборник будет способствовать ослаблению влияния светской литературы, «часто довольно сомнительного свойства, особенно со времени так называемых «свобод» [Там же. С. 125]. Тобольские духовные авторы не отрицали публицистической стороны в сочинении своего земляка, сближая, таким образом, агиографию с публицистической проповедью. Д. Смирнов и К. Киановский сообщают о том, что А.И. Юрьевский работал над своим сочинением десять лет. Всего им было создано около 560 жизнеописаний русских подвижников, кончина которых последовала в XIX в., начиная с 1800 г. [Там же. С. 126]. Три выпуска Патерика в 1912 г. были напечатаны в Тобольске. Отметим, что сборник получил некоторую известность в Европейской России. Так, экземпляр 1-го выпуска находился в библиотеке священномученика протоиерея Иоанна Восторгова (ныне в фонде РГБ).

На страницах Иркутских епархиальных ведомостей в 1903 г. были опубликованы две статьи инспектора Иркутской духовной семинарии Н.Н. Кузнецова, посвященные рассмотрению некоторых аспектов современной русской агиографии. Эти статьи также можно рассматривать как отклик на издание «Житий святых...» Св. Димитрия. Интерес иркутского автора к проблематике не был случайным. Приведем краткие сведения о биографии писателя: уроженец Царского Села, обучавшийся в Царскосельском лицее, а впоследствии в санкт-петербургской семинарии и духовной академии, которую окончил в 1902 г. со степенью кандидата бого-

\footnotetext{
${ }^{1}$ Генезис замысла тобольского автора требует более тщательного рассмотрения в контексте современного ему этапа развития агиографии с учетом деятельности архиепископа Димитрия Самбикина, Никодима Кононова, Е. Поселянина и других авторов.
} 
словия. Тема кандидатского сочинения - «Нравственный смысл юродства и столпничества» (впоследствии переработана в магистерскую диссертацию). Текст диссертации позже (в 1913 г.) был напечатан [16, 17]. В 2000 г. осуществлено репринтное издание данного текста ${ }^{1}$.

По окончании академии Н.Н. Кузнецов в течение года служил инспектором в Иркутской духовной семинарии, после чего продолжал службу в духовных учебных заведениях Новгородской, Ярославской епархий. В 1904 г. принял монашество с именем Алексий и священнический сан и подвизался в монастырях Вологодской епархии, служил в Урмийской Духовной миссии (Персия), духовных учебных заведениях Московской, Нижегородской, Томской епархий. В 1916 г. возведен в сан епископа и проходил дальнейшее служение в Московской, Вятской, Свердловской, Пензенской епархиях. В 1927 г. владыка Алексий был рукоположен в сан архиепископа. После установления советской власти неоднократно подвергался арестам, обыскам, реквизициям, высылкам, тюремному заключению. Приговором тройки при УНКВД по Удмуртской АССР от 15. 11.1938 был приговорен к расстрелу. Виновным себя не признал, фальсифицированные протоколы допросов не подписал. 18 ноября 1938 г. был расстрелян в г. Ижевске. По другим источникам, расстрел состоялся 09.01.1939 [16].

Диссертация Н.Н. Кузнецова в большей степени посвящена рассмотрению юродства и столпничества как видов христианской аскезы, однако в рамках ее он касался и некоторых агиографических аспектов. Сравнение текстов статей в «Прибавлениях к Иркутским епархиальным ведомостям» и книги «Юродство и столпничество» показало, что статьи представляют собой два фрагмента введения названной работы молодого автора. Введение имеет подзаголовок «Значение и сущность аскетических подвигов юродства и столпничества. Задачи исследования» [17. С. 3-44]. Статья «Существенный пробел...» [18] соответствует тексту [17. С. 13-18], а статья «Значение агиобиографии...» [Там же. С. 21-28; 19].

Укажем на некоторые расхождения между фрагментами в книге и публикациях иркутского издания. В статьях епархиальных ведомостей автор убрал упоминание «юродивых и святых столпников» и заменил его «святыми угодниками Божиими», что говорит о том, что рассмотренные им в диссертации вопросы имеют значение не только в рамках аскетики, но и для агиографии как литературного жанра. Другое существенное отличие: перечень приведенных автором сборников «агиобиографических творений», упомянутых в публикации епархиальных ведомостей в качестве источников, значительно короче, чем в монографии, поскольку, по-видимому, не предполагалось печатать полный текст работы. Имеется также ряд несущественных отличий стилистического характера. Внесенная в текст статей правка подчеркивает именно агиографические аспекты сочинения.

Автор статей «Иркутских епархиальных ведомостей» развивал высказывавшуюся многими духовными писателями XIX - начала XX в.

\footnotetext{
${ }^{1}$ В данной работе мы использовали издание 2000 г.
} 
(А. Яхонтов, Г.П. Федотов, а также упомянутые выше тобольские авторы) мысль о том, что «агиобиографические произведения были самым распространенным родом нашей древней письменности для наших предков и составляли не только любимейшее чтение, но, можно сказать, и единственное чтение» [19. С. 48]. Этими словами начинается статья «Значение агиобиографии...». Н.Н. Кузнецов указывает широкий спектр назначения агиографических текстов, объясняющий причины исключительной популярности жанра у русского православного читателя. Отметив нравственноназидательный характер житий, автор статьи подчеркивает важные для него возможности использования произведений агиобиографического жанра в качестве материала для проповедей, притом проповедей публицистического характера: «В них беспрепятственнее можно было указывать недостатки общества и под видом похвалы святому проводить такие взгляды, которые не могли быть, по известным причинам, высказаны прямо, открыто; и когда русские архипастыри затруднялись от своего лица делать прямые обличения господствующего порока, опасаясь преследований власти или окружающей среды, тогда они обыкновенно пользовались житиями святых, которые читали в церкви и списки их распространяли в народе $<\ldots>$. Жития святых... были во все времена наиболее понятным и $<\ldots>$ любимым чтением» [Там же. С. 48-49] Писатель подчеркивал связь жанра с православной догматикой, системой нравственного богословия (этикой), апологией Православной Церкви. Обращение к житиям святых побуждало православных читателей подражать их подвигам и добродетелям, показывало «изображение жизни облагодатствованного человека» - «как она зарождается, развивается и укрепляется... имеет свои переходные степени от совершенства к совершенству, также как и уклонения ко злу» [Там же. С. 50].

Н.Н. Кузнецов затрагивает также вопрос об отличиях отечественной агиологии и агиографии от западной. «Современная же западная наука или вовсе не касается житий святых или, еще хуже - относится к ним сомнительно» [Там же].

Другим важным фактором развития агиографии в Сибири в начале $\mathrm{XX}$ в. можно считать состоявшуюся в первые два десятилетия XX в. канонизацию сибирских святых - святителей митрополита Тобольского Иоанна Максимовича (1916) и Софрония (Кристалевского), третьего епископа Иркутского (1918). Торжество по случаю прославления святителя Иоанна состоялось в Тобольске в 1916 г. На нем присутствовали столичное духовенство, сибирские иерархи, представители духовенства и мирян сибирских епархий. Наиболее распространенная версия истории другого агиографического сборника - «Сибирского Патерика» - связывает инициативу его создания с празднованием прославления святителя Иоанна Максимовича и деятельностью священномученика архиепископа Омского и Павлодарского Сильвестра (Ольшевского). В 1917 г. в статье Омских епархиальных ведомостей по случаю юбилея преосвященного Сильвестра его почитатель писал: «Вы зовете и увлекаете нас на трудном пути спасения живыми примерами Св. Угодников, живших и спасавшихся в миру, полагая труд и на 
составление Сибирского Патерика» [20. С. 24]. Омский исследователь А.М. Лосунов приводит следующий вариант возникновения идеи «Сибирского Патерика»: «Возвратясь с этих торжеств в Омск епископ Сильвестр (Ольшевский) стал готовить к изданию «Сибирский Патерик» [7. С. 157]. Отметим, что митрополит Иоанн (Снычев) подчеркивал роль будущего митрополита Мануила (Лемешевского), служившего тогда в Семипалатинской епархии, как активного участника рассматриваемого проекта [21. С. 44]. Точка зрения митрополита Иоанна находит косвенное подтверждение в работе игумена Марка (Лозинского). Среди патериков, возникших после 1917 г., он называет несколько сочинений митрополита Мануила, созданных в рамках названного жанра: Новый Соловецкий, Серпуховской, Оренбургский, Бузулукский и Цветники: Пешношский, Оренбугский и др. [5. С. 74-75]. Степень участия отдельных составителей предполагаемого «Сибирского Патерика» в работе над текстом нуждается в самостоятельном изучении при условии разыскания самого памятника или его фрагментов. Приведенные игуменом Марком данные позволяют увидеть причастность сибирской агиографии к формированию новой общерусской традиции, которая имела продолжение в советский период истории Русской Православной Церкви.

Во время тобольских торжеств идея «Сибирского Патерика» обсуждалась представителями делегаций сибирских епархий. Проспект предполагаемого издания в 1916 г. был опубликован на страницах омского епархиального периодического издания [22]. В публикации Омских епархиальных ведомостей можно найти некоторые следы состоявшегося обсуждения: «Сочувственно отнеслись к мысли об издании «Сибирского Патерика» и другие Преосвященные архипастыри, особенно сибирские, посетившие нынешним летом г. Тобольск по случаю прославления святителя Иоанна. Один из архипастырей писал преосвященному Сильвестру так: «Лобызаю Вашу прекрасную мысль об издании Сибирского Патерика» (из письма епископа Зосимы)» [Там же. С. 9]. «Прислал свое благословение на этот труд маститый архипастырь Московский митрополит Макарий, откликнувшийся на это благое дело <..> письмом от 22 января с. г. на имя преосвященного Сильвестра» [Там же. С. 8].

Статья «Предполагаемое издание “Сибирского Патерика”» содержит пространное обоснование актуальности поставленной задачи: «Мы мало знаем своих родных, близких нам по месту жительства подвижников благочестия, мало и чтим их» [Там же. С. 7]. Особо подчеркивается необходимость знакомства с их трудами и подвигами новых поселенцев региона. Автором идеи Патерика в статье назван епископ Омский и Павлодарский преосвященный Сильвестр. Осуществляться проект должен был Омским епархиальным Богородичным Братством. Митрополит Московский Макарий (Невский), бывший алтайский миссионер, напомнил о необходимости включить в состав Патерика имя подвижницы Анастасии (в схиме Афанасии), подвизавшейся в Алтайской духовной миссии.

Полное заглавие сборника выглядело следующим образом: «Сибирский Патерик. Жизнеописания прославленных угодников Божиих и непрослав- 
ленных подвижников веры и благочестия, кои родились или подвизались в пределах Азиатской России».

В статье епархиальных ведомостей представлен корпус авторов предполагаемого сочинения, изложены некоторые установки, которыми предполагали руководствоваться составители Патерика. Остановимся подробнее на этом вопросе. «Сибирский Патерик», как по характеру изложения, так и по внешнему виду, - писал автор статьи, - предполагается издать по образцу «Житий святых», составленных по руководству Четьих-Миней святителя Димитрия Ростовского на русском языке издания Московской Синодальной Типографии». Далее приведен перечень, включающий имена 150 святых и подвижников благочестия. Статья Омских епархиальных ведомостей вместе с проектом Патерика была перепечатана Тобольским епархиальным периодическим изданием с указанием источника [23].

Редакция Тобольских епархиальных ведомостей следила за реакцией на торжество по поводу прославления митрополита Иоанна Максимовича в других епархиях Сибири. Так, в епархиальном периодическом издании Тобольска приведены сведения о торжествах, состоявшихся в Омске. В числе мероприятий празднования отмечается необходимость «отпечатать 10000 экз. листков о житии Св. Иоанна Максимовича и труд этот поручить свящ. о. Илии Фокину, как составителю жития святителя для будущего Патерика Сибирских святых» [24].

Преосвященный Сильвестр предложил томскому Церковному историко-археологическому обществу принять участие в составлении Сибирского Патерика, в который согласно приложенному проспекту должны войти жизнеописания выдающихся в Томской епархии лиц или по святости жизни или по своей церковной деятельности». Названы имена старца Феодора Кузьмича, иеромонаха Алтайской миссии Димитрия, иерея Феодора Краснопевцева, блаженной старицы Домны и др. Соответствующая информация появилась на страницах Томских епархиальных ведомостей [25]. Как сообщает автор заметки, «комитет охотно принял предложение Преосвященного Сильвестра об участии в составлении Сибирского Патерика и постановил приступить немедленно к работе по мере отыскания необходимых материалов». Данная заметка была перепечатана Омскими и Иркутскими епархиальными ведомостями [26, 27].

Таким образом, рассмотренные публикации епархиальных ведомостей позволяют предполагать, что осуществление проекта «Сибирского Патерика» превращалось в общесибирское дело, что, на наш взгляд, отражало важный момент самосознания сибиряков. Но впереди был 1917 г. ...

В заключение упомянем, о том, что история агиографии в Сибири в годы советской власти нуждается в самостоятельном изучении, в том числе и вопрос о трансформации замысла рассматриваемого здесь «Сибирского Патерика». О существовании такого направления в сибирской агиографии и агиологии свидетельствует многолетняя плодотворная деятельность митрополита Варфоломея (Городцева), архимандрита Иннокентия (Просвирнина), а также протоиереев Б.И. Пивоварова и А.И. Дмитрука и др. 
Некоторые эпизоды деятельности архимандрита Иннокентия как агиографа Сибири затрагиваются в публикациях и статьях сборников, посвященных памяти о. архимандрита ([28, 39] и др.). Труды о. Бориса Пивоварова широко представлены на страницах «Православной энциклопедии» и других изданий, а составленный о. Анатолием Дмитруком «Патерик Сибирских святых и подвижников благочестия» увидел свет в 2006 г. в г. Единец (Молдова) [30].

\section{Лuтература}

1. Житийная литература / игум. Андроник (в соавт) // Православная энциклопедия. M., 2008. T. 19. C. 283-345.

2. Чернышова Н.К. Православные святые и подвижники благочестия в изданиях Сибири и Дальнего Востока // Традиция и современность. 2014. № 15. С. 133-139.

3. Чернышова Н.К. Сибирские святые и подвижники благочестия в агиографических сборниках конца XIX - начала XX в. // Региональные общественные и политические идеи в произведениях деятелей русской культуры XVI-XXI вв. Новосибирск, 2015. C. 213-222.

4. Голубинский E.E. История канонизации святых в русской церкви. Репр. изд. М., 1903. М., 1998. С. 3-10.

5. Марк (Лозинский), игум. Из истории Патериков // Журн. Моск. Патриархии. 1973. № 3. C. $72-75$.

6. Коновалова Е.Н. Книга Тобольской губернии. 1790-1917 гг.: свод. каталог местн. изд. Новосибирск, 2006. 628 с.

7. Лосунов А.М. Омская епархия: история и современность // Актуальные проблемы исторической науки: общее и уникальное в истории. Омск, 2009. С. 151-171.

8. Объявление. В главном складе синодальных изданий (Москва, Синодальная типография). Поступили в продажу: Жития святых на русском языке, изложенные по руководству Четьих-Миней св. Димитрия Ростовского с дополненями из Пролога // Тобол. епарх. ведомости. 1902. № 21. Отд. офиц. С. 369-372.

9. В Московской Синодальной типографии печатается новое издание: Минеи-Четьи на русском языке в 12 книгах. Жития святых, изложенные по руководству ЧетьихМиней Св. Димитрия Ростовского, с дополнениями из Пролога, объяснит. примеч. и изображениями святых и праздников. Поступили в продажу [кн. 1] // Том. епарх. ведомости. 1902. № 20. Отд. неофиц. С. 30.

10. Юрьевский А. Минеи-Четьи на русском языке (издание Московской Синодальной типографии) // Тобол. епарх. ведомости. 1904. № 22. Отд. неофиц. С. 442-448.

11. Отношение управляющего Московскою Синодальною типографиею на имя Его Преосвященства // Тобол. епарх. ведомости. 1902. № 21. Отд. офиц. С. 371.

12. Д.Н.Н. Лоллий (Юрьевский Александр Иванович) // Православная энциклопедия. М., 2016. Т. 41. С. 409-410.

13. К жизнеописанию святителя Иоанна Максимовича / публ. А. Юрьевского. Киев, [1916]. $33 \mathrm{c}$.

14. Ю. Преосвященный Варлаам I, архиепископ Тобольский († 1802) // Тобол. епарх. ведомости. 1912. № 10. Отд. неофиц. С. 203-209, № 11. С. 232-241.

15. Смирнов Д., Киановский К. От Совета Тобольского епархиального братства // Школьный листок: прилож. к Тобол. епарх. ведомостям. 1912. № 16. С. 125-126.

16. Алексий (Кузнецов Николай Николаевич). URL: http://kusl.pstbi.ccas.ru/bin/db.exe/ ans/newmr/?hyz9EJxGHoxl... (дата обращения: 28.04.2016).

17. Алексий (Кузнецов). Юродство и столпничество: религиозно-психологическое, моральное и социальное исследование. СПб., 1913. [4], 410 с. 
18. Кузнецов H. Существенный пробел в нашей агиобиографической литературе // Прибавления к Иркутским епархиальным ведомостям. 1903. № 2. С. 26-32.

19. Кузнецов H. Значение агиобиографии и ее историческая достоверность // Там же. № 3. С. 48-55.

20. Двадиатилетие священнослужения Преосвященного Сильвестра, епископа Омского и Павлодарского // Ом. епарх. ведомости. 1917. № 8. Ч. неофиц. С. 22-29.

21. Иоанн (Снычев). Жизнь и служение митрополита Мануила: бигр. очерк. Самара, 1997. $316 \mathrm{c}$.

22. Предполагаемое издание «Сибирского Патерика» // Омские епарх. ведомости. 1916. № 37. C. 7-12.

23. Предполагаемое издание «Сибирского Патерика» // Тобол. епарх. ведомости. 1916. № 42. Отд. неофиц. С. 868-873.

24. Отклики иноепархиальной печати по поводу прославления Святителя Иоанна Максимовича, Митрополита Тобольского и Сибирского // Тобол. епарх. ведомости. 1916. № 13. Отд. неофиц. С. 204-205.

25. Собрания Историко-Археологического Общества // Том. епарх. ведомости. 1916. № 21. Отд. неофиц. С. 744-745.

26. Собрания Историко-Археологического общества // Омские епарх. ведомости. 1917. № 3. Часть неофиц. С. 3.

27. Собрания Историко-Археологического общества // Прибавления к Иркут. епарх. ведомостям. 1917. № 1. С. 35-36.

28. Блаженны чистые сердцем / сост. О.В. Курочкина. М., 2008. 448 с.

29. Православная культура России в трудах архимандрита Иннокентия (Просвирнина). Новосибирск, 2009. 100 с.

30. Дмитрук А. Патерик сибирских святых и подвижников благочестия. Единец, 2006. $608 \mathrm{c}$.

The Problems of Hagiography in the Spiritual Periodicals of Siberia in the Early 20th Century

Vestnik Tomskogo gosudarstvennogo universiteta. Filologiya - Tomsk State University Journal of Philology. 2019. 60. 247-257. DOI: 10.17223/19986645/60/16

Nadezhda K. Chernyshova, State Public Scientific and Technological Library of the Siberian Branch of the Russian Academy of Sciences (Novosibirsk, Russian Federation). E-mail: chernyshova@gpntbsib.ru

Keywords: hagiography, The Lives of the Saints, Paterikon, saints, prelates, project, A.I. Yuryevsky (Archbishop Lolliy), Archibishop Sylvester (Olshevsky), Metropolitan Manuel (Lemeshevsky), N.N. Kuznetsov (Archbishop Alexiy), Tobolsk, Tomsk, Omsk, Irkutsk eparchy gazettes.

The article discusses the history of creation in Siberia of projects of two hagiographical miscellanies - New Holy Russian Paterikon (1912) in Tobolsk and Siberian Paterikon (1916) in Omsk. The belonging of these phenomena to an important spiritual tradition of Siberian hagiography which developed in the country in the second half of the 19th - early 20th centuries - the wide spread of so-called "Russian Paterikons" in Russia - is substantiated. The factors of church-social and cultural life of Russia in the beginning of the 20th century which determined the appearance of these projects are identified. The factors were: the publication of The Lives of the Saints in Russian told on the basis of the Great Menaion Reader by Saint Dmitry of Rostov with a supplement from The Prologue (Books 1-12. Moscow, 1902-11) by the Moscow Synodal Printing House and the canonization of Siberian prelates John Maximovich, Metropolitan of Tobolsk, and Sophronius Kristalevsky, Bishop of Irkutsk. The publications of Tobolsk, Tomsk, Irkutsk and Omsk eparchy gazettes that reflected the development of the new ideas (advertisements, reviews, the Siberian Paterikon project and the correspondence accompanying it, the response of Siberian eparchies' clergy to the 
appearance of the plans of the miscellanies and of the miscellanies themselves, etc.) are analyzed. The role of the organizers and executors of the projects in the creation of the Paterikons is emphasized. The views of Siberian spiritual writers on the problem of hagiography as a traditional genre in the conditions of a revolutionary crisis and the value of Siberian Paterikon as a factor consolidating the Orthodox population of Siberia are analyzed for the first time. The hypotheses are expressed of the transformation of Siberian Paterikon into a general Siberian project and of its possible influence on the development of Siberian hagiography in the Soviet period, as evidenced, in particular, by the long-term fruitful activities of Metropolitan Varfolomey (Gorodtsev), Archimandrite Innokentiy (Prosvirnin), Archpriests B.I. Pivovarov and A.I. Dmitruk, and others.

\section{References}

1. Andronik. (2008) Zhitiynaya literatura [Hagiography]. In: Pravoslavnaya entsiklopediya [Orthodox Encyclopedia]. Vol. 19. Moscow: Tserkovno-nauchnyy tsentr "Pravoslavnaya entsiklopediya". pp. 283-345.

2. Chernyshova, N.K. (2014) Pravoslavnye svyatye i podvizhniki blagochestiya v izdaniyakh Sibiri i Dal'nego Vostoka [Orthodox saints and men of piety in the publications of Siberia and the Far East]. Traditsiya $i$ sovremennost'. 15. pp. 133-139.

3. Chernyshova, N.K. (2015) Sibirskie svyatye i podvizhniki blagochestiya v agiograficheskikh sbornikakh kontsa XIX - nachala XX v. [Siberian saints and men of piety in hagiographic collections of the late 19th - early 20th centuries]. In: Regional'nye obshchestvennye i politicheskie idei v proizvedeniyakh deyateley russkoy kul'tury XVI-XXI vv. [Regional social and political ideas in the works of figures of Russian culture of the 16th-21st centuries]. Novosibirsk: [s.n.]. pp. 213-222.

4. Golubinskiy, E.E. (1998) Istoriya kanonizatsii svyatykh v russkoy tserkvi [The history of the canonization of saints in the Russian church]. Moscow: Krutitskoye patriarsheye podvor'ye, Obshchestvo lyubiteley tserkovnoy istorii. pp. 3-10.

5. Mark (Lozinskiy). (1973) Iz istorii Paterikov [From the Patericon History]. Zhurn. Mosk. Patriarkhii. 3. pp. 72-75.

6. Konovalova, E.N. (2006) Kniga Tobol'skoy gubernii. 1790-1917 gg.: svod. katalog mestn. izd. [Book of the Tobolsk province. 1790-1917: cat. of local ed.]. Novosibirsk: SPSTL SB RAS.

7. Losunov, A.M. (2009) Omskaya eparkhiya: istoriya i sovremennost' [Omsk diocese: history and modernity]. Aktual'nye problemy istoricheskoy nauki: obshchee $i$ unikal'noe $v$ istorii. pp. 151-171.

8. Tobol'skie eparkhal'nye vedomosti. (1902) Ob"yavlenie [Advertisement]. Tobol'skie eparkhal'nye vedomosti. Official Part. 21. pp. 369-372.

9. Tobol'skie eparkhal'nye vedomosti. (1902) V Moskovskoy Sinodal'noy tipografii pechataetsya novoe izdanie... [A new edition is being printed at the Moscow Synodal Printing House...]. Tomskie eparkhal'nye vedomosti. Unofficial Part. 20. p. 30.

10. Yur'evskiy, A. (1904) Minei-Chet'i na russkom yazyke (izdanie Moskovskoy Sinodal'noy tipografii) [Great Menaion Reader in Russian (edition of the Moscow Synodal Printing House)]. Tobol'skie eparkhal 'nye vedomosti. Unofficial Part. 22. pp. 442-448.

11. Tobol'skie eparkhal'nye vedomosti. (1902) Otnoshenie upravlyayushchego Moskovskoyu Sinodal'noyu tipografieyu na imya Ego Preosvyashchenstva [The Moscow Synodal Printing House manager's address to the name of the Right Reverend]. Tobol'skie eparkhal'nye vedomosti. Official Part. 21. p. 371.

12. Anon. (ed.) (2016) Pravoslavnaya entsiklopediya [Orthodox Encyclopedia]. Vol. 41. Moscow: Tserkovno-nauchnyy tsentr "Pravoslavnaya entsiklopediya". pp. 409-410.

13. Yur'evskiy, A. (1916) K zhizneopisaniyu svyatitelya Ioanna Maksimovicha [On the biography of St. John Maximovich]. Kiev: [s.n.]. 
14. Yu. (1912) Preosvyashchennyy Varlaam I, arkhiepiskop Tobol'skiy [His Grace Varlaam I, Archbishop of Tobolsk]. Tobol'skie eparkhal'nye vedomosti. Unofficial Part. 10. pp. 203-209; 11. pp. 232-241.

15. Smirnov, D. \& Kianovskiy, K. (1912) Ot Soveta Tobol'skogo eparkhial'nogo bratstva [From the Council of the Tobolsk diocesan brethren]. Shkol'nyy listok: prilozhennie $k$ Tobol'skim eparkhal'nym vedomostyam. 16. pp. 125-126.

16. St. Tikhon's Orthodox University et al. (n.d.) Aleksiy (Kuznetsov Nikolay Nikolaevich). [Online] Available from: http://www.pstbi.ccas.ru/bin/ nkws.exe/koi/nm/?HYZ9EJxGHoxITYZCF2JMTdG6Xbu*euKesOWd60W8suShdSOicW0B e8eieu0d66qceeufc8KWeCQd**. (Accessed: 28.04.2016). (In Russian).

17. Aleksiy (Kuznetsov). (1913) Yurodstvo i stolpnichestvo: religiozno-psikhologicheskoe, moral'noe $i$ sotsial'noe issledovanie [Foolishness for Christ and stylitism: religious, psychological, moral and social research]. St. Petersburg: [s.n.].

18. Kuznetsov, N. (1903) Sushchestvennyy probel v nashey agiobiograficheskoy literature [A significant gap in our hagiobiographical literature]. Pribavleniya $k$ Irkutskim eparkhial'nym vedomostyam. 2. pp. 26-32.

19. Kuznetsov, N. (1903) Znachenie agiobiografii i ee istoricheskaya dostovernost' [The value of hagiobiography and its historical reliability]. Pribavleniya $k$ Irkutskim eparkhial'nym vedomostyam. 3. pp. 48-55.

20. Omskie eparkhal'nye vedomosti. (1917) Dvadtsatiletie svyashchennosluzheniya Preosvyashchennogo Sil'vestra, episkopa Omskogo i Pavlodarskogo [The twentieth anniversary of the clergy of Bishop Sylvester, Bishop of Omsk and Pavlodar]. Omskie eparkhal'nye vedomosti. Unofficial Part. 8. pp. 22-29.

21. Ioann (Snychev). (1997) Zhizn'i sluzhenie mitropolita Manuila: bigr. ocherk [Life and Ministry of Metropolitan Manuil: a biography article]. Samara: Pravoslavnaya Samara.

22. Omskie eparkhal'nye vedomosti. (1916) Predpolagaemoe izdanie "Sibirskogo Paterika" [Planned publication of Siberian Paterikon]. Omskie eparkhal'nye vedomosti. 37. pp. 7-12.

23. Tobol'skie eparkhal'nye vedomosti. (1916) Predpolagaemoe izdanie "Sibirskogo Paterika" [Planned publication of Siberian Paterikon]. Tobol'skie eparkhal'nye vedomosti. 42. Unofficial Part. pp. 868-873.

24. Tobol'skie eparkhal'nye vedomosti. (1916) Otkliki inoeparkhial'noy pechati po povodu proslavleniya Svyatitelya Ioanna Maksimovicha, Mitropolita Tobol'skogo i Sibirskogo [Responses of another diocesan press regarding the glorification of St. John Maximovich, Metropolitan of Tobolsk and Siberia]. Tobol'skie eparkhal'nye vedomosti. 13. pp. 204-205.

25. Tomskie eparkhal'nye vedomosti. (1916) Sobraniya Istoriko-Arkheologicheskogo Obshchestva [Meetings of the Historical and Archaeological Society]. Tomskie eparkhal'nye vedomosti. 21. pp. 744-745.

26. Omskie eparkhal'nye vedomosti. (1917) Sobraniya Istoriko-Arkheologicheskogo obshchestva [Meetings of the Historical and Archaeological Society]. Omskie eparkhal'nye vedomosti. 3. pp. 3.

27. Pribavleniya k Irkutskim eparkhal'nym vedomostyam. (1917) Sobraniya IstorikoArkheologicheskogo obshchestva [Meetings of the Historical and Archaeological Society]. Pribavleniya k Irkutskim eparkhal'nym vedomostyam. 1. pp. 35-36.

28. Kurochkina, O.V. (ed.) (2008) Blazhenny chistye serdtsem [Blessed are the pure in heart]. Moscow: Ikhtios.

29. Anon. (2009) Pravoslavnaya kul'tura Rossii v trudakh arkhimandrita Innokentiya (Prosvirnina) [The Orthodox culture of Russia in the writings of Archimandrite Innocent (Prosvirnin)]. Novosibirsk: Pravoslav. gimnaziya vo imya Prp. Sergiya Radonezhskogo.

30. Dmitruk, A. (2006) Paterik sibirskikh svyatykh $i$ podvizhnikov blagochestiya [Patericon of Siberian saints and men of piety]. Edinets: Edinetsko-Brichanskaya Eparkhiya. 